\title{
Loess Cave Dwelling under the Conditions of Heavy Rain Destruction Form and Prevention Measures
}

\author{
W. Tian*, X.M. Gao, W.T. Shi \\ Chang' anuniversity, \\ Xi’an, Shaanxi, 710061, \\ China \\ tianwei_812@163.com
}

\begin{abstract}
Base on plenty of field investigation and study, the loess cave dwellings were specifically divided into different types. Under the condition of continuous heavy rain, the loess cave dwelling destructions were summarized and analyzed to find out the reasons and the corresponding prevention measures.
\end{abstract}

Keywords_loess cave; heavy rain; destruction; loess joint

\section{INTRODUCTION}

As a popular dwelling form on the loess plateau, Loess cave has good insulation resistance with the stability of indoor temperature and humidity. It is an ideal natural place for human living and food storage. Cave dwelling buildings are mainly located in Shanxi, Shaanxi, Gansu, Henan, Ningxia and other places [1].

The main material of loess cave buildings is the loess. Because buildings are directly exposed to nature, there are still some security risks. In July 2013, Yan'an Shaanxi sustained heavy rainfall occurred from 7th to the 12th, causing landslides and cave collapse which brought about 13 fatalities, 4 missing and 15 injured [2]. Loess cave dwellings under continuous heavy rainfall have various types of damage which caused further disasters frequently. The domestic and foreign scholars carried out many related types of research on the construction of the loess cave dwelling for a long time, such as the village of Yan'an zaoyuan [3] and loess cave waterproof technology [4], Han studied the influence on the stability of the cave, When the abandoned cave overlying soil had vertical joints, rain along the joint reached the cave surrounding soil [5]. Shi et al studied the problems on earthquake fortification in present construction of civilian buildings and the corresponding seismic prevention counter measures were put forward [6]. H. Yang studied the failure forms of cave under earthquake, and put forward some protective measures [7].whereas seldom involved the research relating to loess cave disasters in the case of continuous heavy rainfall. It is difficult for us to gain a thorough understanding of the types of disaster and disaster mechanism of loess cave under continuous heavy rainfall. It is necessary to conduct a comprehensive investigation on loess cave and an analysis in disaster types under continuous heavy rainfall. The appropriate measures are proposed, which is of great significance for protecting the lives and the property of the residents. Besides, it is conducive to protect this traditional residential architecture [8].

\section{THE TYPE OF CAVE}

At present, the cave can be divided into three types in terms of construction method mainly: the excavation-style cave, masonry-style cave, and half masonry style semi excavation cave [9]. The excavation-style cave is the cave excavated in the mountain or the walls of the pit. The remarkable characteristics of this cave are simple construction method and low cost. It makes the best use of present nature landform, excavating underground or in the hillside. This type cave can save much cultivated land area. But because of inconvenience traffic and other reasons, the hillside cave is gradually eliminated. Masonry-style cave refers to using adobe, brick, stone and other masonry block material constructive the cave on the ground or excavated pit. According to the materials, the cave can be divided into the soil cave, brick cave, stone cave and so on. This kind of cave consists of a straight wall, arch, vault, and side filling the soil and other components. This type of cave has a higher construction cost compared to the excavation-style cave. The cave is characterized by its convenience traffic and has much advantage inhuman production and life. It is an effective measure that can solve the pressure problems of housing. This kind of cave is divided into two parts along the length direction of the cave. The front part is made of masonry to ensure the safety of the whole cave and the latter part is cave excavation.

\section{Disaster Types of LOESS CAVE IN THE CASE OF CONTINUOUS HEAVY RAINS}

After some interviews with local residents in Yan'an, Yulin, Sanyuan and other places of loess cave, this paper summarized the loess cave damage types under the condition of continuous heavy rain. The failure modes classified as follows: the partial collapse of the kiln roof, Cave overcall slump, Cave collapse, and Kiln seepage. 


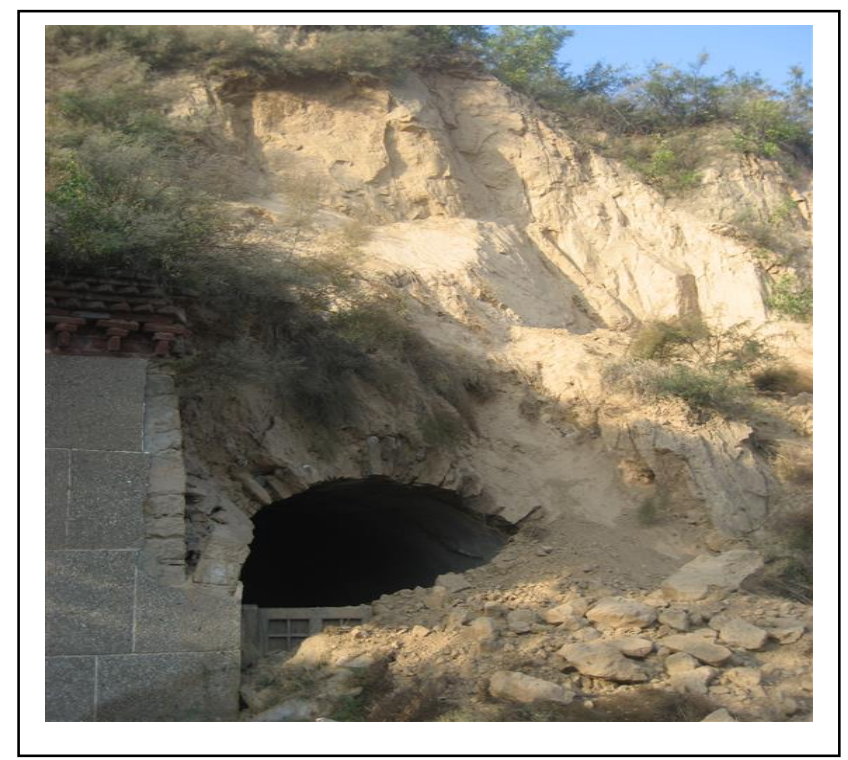

Fig. 1. Partial collapse of the kiln roof.

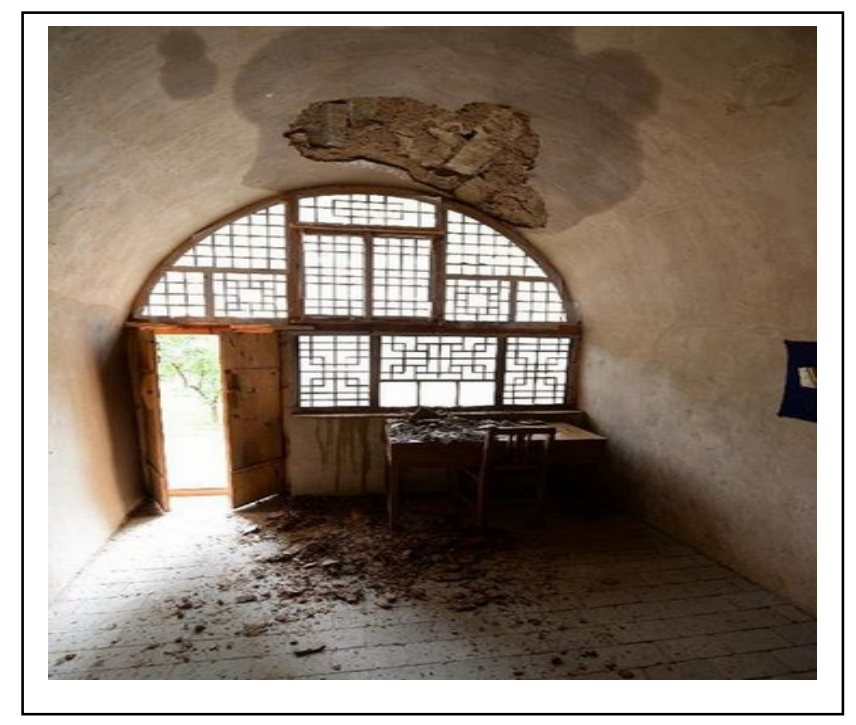

Fig. 2. Kiln seepage.

Partial collapse of the kiln roof mainly happens on the top of the kiln face. As shown in Fig. 1, if the kiln face is steep, or the cave lies in the ancient soil of weathered layer, continuous heavy rainfall will increase the weight of this part of the soil, weaken its shear strength. It will lead to the crown slump and further reduce the thickness of the protective layer of the front of the cave, causing the collapse of the front part of the cave. Cave overcall slump is more common in the hillside cave excavation style. At the high cliff area, artificial slope cutting area, and ancient landslide area, continuous heavy rains cause the landslides and lead to an overall slump cave. Cave collapse is a type of cave overall incidence of disaster damage, which is common in the excavation-style cave. Under the continued infiltration of rainwater, the soil at the top of the cave became humidifier, the weight increased, and the intensity became lower. It is difficult to ensure the overall stability of the kiln arch. It will lead to the collapse of the whole cave. Kiln seepage mainly happens on the caves with small overlaying soil thickness. The soil layer on the top of the cave exist loess joints and root holes, the rain will be infiltration along the joints and root holes, and will form a seepage area at the top of the kiln. As shown in Fig. 2, the rainwater made the weight of this part of the region increased, and led to flaking the top soil.

\section{The ANALysis of The CAUSE OF A Disaster ABOUT LoEsS CAVE DWELLING UNDER THE CONDITION OF CONTINUOUS HEAVY RAINFALL}

The main cause for the disaster is the joint. Loess joints can be generally classified into primary joints, structural joints, and secondary joints. Primary joints are generated in the process of loess accumulation. Joint spacing is a few centimeters commonly. The tendency is generally not straight, and plane distribution is irregular and generally not well versed its loess. Structural joints formed by tectonic geologic stress on the soil layer, Structural joints generally through the loess stratification [10]. Secondary joints mainly include weathering joints and unloading joints. According to the different kind of joints, the soil is divided into various geometric shapes [11]. Before the excavation of caves, for the purposes of digging needs, people often cut slope on the slopes or cliff body firstly, which will make the joints in the loess further developed during unloading. After the excavation of the cave, all kinds of joints will further develop, and the integrity of soil structure will decrease.

When continuous heavy rainfall occurs, part of the rain forms runoff on the soil surface without enough time to infiltrate. It washes the surface of the cave, gradually weakens the protective layer of the loess cave dwelling. Finally, it will lead to the surface local slumping loess cave dwelling collapsed. On the other hand, as the rain infiltration, at the top of soil the weight increase and will make originally cementation of loess particles suspended or under the action of free water and joint the gap flow along the soil, thus destroying the structure and integrity of the soil itself and reduces the strength of loess. Moreover, the rain goes down the joints and plant root holes infiltration, which made some of the originally weak structural plane further weaken and deep. The overall stability of the loess cave dwelling was damaged. In addition, the continuous heavy rainfall could also lead to the slope body unstable, eventually led to the cave of overall slump.

\section{The Prevention Measures of Loess Cave Dwelling DISASTER}

\section{A. The Rational Choice of the Location of the Loess Cave Dwelling}

The location of the loess cave dwelling should try to avoid the well-developed joint slayer. When there is the need for cutting slope, it is necessary to determine the height of the artificial soil to maintain the stability of soil cliff, Wang Jingming [10], etc. (1996) argue that Maintaining stability of the cave at the top of the soil arch has relevant with the minimum thickness of overlying soil and wide functions, namely: 


$$
H=1.1(b+h)
$$

where $\mathrm{H}=$ the thickness of overlying soil;

$\mathrm{b}=$ the width of the cave;

$\mathrm{h}=$ the height of the cave.

Loess caves in $3 \mathrm{~m}$ wide, $2.5 \mathrm{~m} \sim 3 \mathrm{~m}$ high, turns the soil thickness is greater than 6 mmore stable. The field investigation, in general, is stable when turns the soil thickness is greater than $4 \mathrm{~m}[12]$.

\section{B. The Reasonable Drainage Design}

Due to the rain infiltration in the continuous heavy rain, the soil at the top of the cave water content and weight increase, resulting in a decline in its carrying capacity. Therefore, it stresses on the various quality and safety requirements of drainage at the top and the side. The rainwater should be drained away quickly.

\section{Do Well Waterproof Processing}

The emphasis of prevention and cure should be put on the waterproof layer between the arch ring and the soil on top of the arch to prevent the rainwater infiltration arch ring. The waterproof layer can adopt the method of dry laid linoleum or "soil water potential" [13], which from the modern soil physics. Set a layer of sand at the top of the loess in the cave, In the literature [14] pointed out that sand buried deeply in 0.5 $\mathrm{m}$ to $1.2 \mathrm{~m}$, block water time sustained3-5h, resistance of water in between 10\%-30\% (relative to the homogeneous soil), The depth of wetting front movement can be reduced by $25 \%$ $15 \%$.

\section{CONCLUSIONS}

According to many types of research, this paper summarizes the type of loess cave dwelling disaster under the condition of continuous heavy rainfall and analyzes the causes of these disasters. It helps to take the prevention measures, such as the rational choice of the loess cave dwelling location, the determination of the reasonable cutting slope height, the reasonable drainage design, and the methods of setting the waterproof layer. All of these above have realistic significance to protect the resident lives and property, and they are conducive to the protection and promotion of the loess cave dwelling.

\section{REFERENCES}

[1] J.Y. Hou, and J. Wang, China Cave Dwellings, Henan Science and Technology, Press, pp. 28. 1999.

[2] Information on http://news.xinhuanet.com/politics/2013-07/12/c _116513980.htm

[3] J.P. Liu, Entered the New Era of Green Cave Dwelling, China Economic Herald. 2003.

[4] S.H. Yu, Road Engineering, Wuhan University of Technology Press. 2000.

[5] J.M. Han, and S.Q. Su, "Stability Analysis of Weibei Pitted Loess Cave Dwellings in Rainfall Infiltration,” J. Arch. Civil Eng. vol. 29, pp. 104110, 2012.

[6] Y.C. Shi, X.W. Lin, and L.M. Wang, "Earthquake Damage Characteristics of Raw Soil Buildings in Loess Areas and Disaster Prevention Countermeasures,” J. Nat. Dis. vol. 12, pp. 87-92, 2003

[7] H. Yang, The Investigation of Destruction of Cave in Northern Shaanxi, J, Yanan University (Natural Science Edition), vol. 30, pp. 84-86, 2011

[8] X.J. Liu, T.X. Wang, Y.Q. Han, and Y.F. Zhao, "Research and Analysis of the Loess Cave Dwelling Disaster.” Chinese J. Underground Space Eng. vol. 3, pp. 996-999, 2007.

[9] Y.X Zhang, and X.Y. Tian, "Cave Damage Cause and Protective Measures.” J. Northwest Sci. Technol. U. Agr. (Nat. and Sci), vol. 32 supp, pp. 145-149, Nov. 2004.

[10] J.M. Wang, Theory and Application of Structural Joint of Loess, China Water Power Press, pp. 14-18, 1996.

[11] L.C. Feng, \& Y.W. Zheng, China Collapsible Loess, China Railway Press, 73-74, 2007.

[12] C.J. Wu, Z.M. Gan, and C.P. Meng, "Stability analysis of the Cave in Northern Shaanxi Loess Hilly Area.” J. Shaanxi Normal U. (Nat. and Sci), vol. 33, pp. 119-122, (Sep.2005).

[13] X.L. Yao, and Z.S. Cheng, Soil Physics. Beijing Agricultural Press. 1986.

[14] J.F. Zhang, W.Y. Wang, Z.W. Yang, and Y. Gao, "To Prevent and Reduce the Permeability of Northwest Loess Cave.” J. China Agr. U., pp. 88-91, 1997. 